http://jmscr.igmpublication.org/home/ ISSN (e)-2347-176x ISSN (p) 2455-0450

crossref DOI: https://dx.doi.org/10.18535/jmscr/v7i9.92

Journal Of Medical Science And Clinical Research

\title{
Comparative Study of Intraocular Pressure Measured by Non-Contact and Goldmann Applanation Tonometer and their Correlation with Corneal Thickness in a General Population
}

\author{
Authors \\ Dr Santanu Das ${ }^{1}$, Dr Nayana Nagesh ${ }^{2}$, Dr Kiran Kumar $\mathbf{L}^{3}$ \\ ${ }^{1}$ MS Ophthalmology, Department of Ophthalmology, Kempegowda Institute of Medical Sciences, \\ Bangalore \\ ${ }^{2}$ Junior Resident, Department of Ophthalmology, Kempegowda Institute of Medical Sciences, Bangalore \\ ${ }^{3}$ MS Ophthalmology, Associate Professor, Department of Ophthalmology, Kempegowda Institute of \\ Medical Sciences, Bangalore \\ *Corresponding Author
}

Dr Santanu Das

MS Ophthalmology, Department of Ophthalmology, Kempegowda Institute of Medical Sciences, Bangalore

\begin{abstract}
Purpose: To compare the intraocular pressure (IOP) measured by Non-Contact tonometer (NCT) and Goldmann Applanation tonometer (GAT) and their correlation with central corneal thickness (CCT) as well as the reliability of each tonometer.

Methods: 500 patients (1000 eyes) attending the ophthalmology OPD aged 18 years and above were taken up for the study. Patients with anterior and posterior segment pathologies like corneal ulcer, leukoma, staphyloma, corneal lacerations, ectatic corneal conditions, corneal dystrophies, oedema, perforations, acute angle closure glaucoma, retinal detachments, vitreous haemorrhage and unwilling patients were excluded from the study. IOP was recorded using NCT and GAT after assessing the patient's visual acuity. Following IOP measurement, central corneal thickness (CCT) value of each patient was measured using pachymetry. All the data were collected and tabulated for statistical analysis to obtain results.

Results: In the present study there were 256 males (51.2\%) and 244 females (48.8\%). The mean CCT in males was $0.5350 \mathrm{~mm}$ and in females $0.5340 \mathrm{~mm}$ respectively. The mean IOP measured by NCT is $16.43 \mathrm{~mm}$ hg whereas the mean IOP measured by GAT is $15.43 \mathrm{~mm}$ hg. IOP measured by NCT is significantly higher than the IOP measured by GAT ( $p<0.001)$. When correlated with CCT all the tonometers show significant correlation with GAT showing the strongest significant correlation. NCT overestimates IOP in normal, thin and thicker corneas when compared to GAT and are statistically significant.

Conclusion: From the present study we can conclude that IOP measured by NCT is higher than GAT. NCT values are significantly higher than GAT values in thin and normal corneas whereas it overestimates more in thicker corneas. All the tonometers show significant correlation with CCT with GAT showing the strongest significant correlation in this study. So, it is always advisable to measure the corrected IOP for each and every patient after taking into account the CCT of that particular person.

Keywords: Non-contact tonometer, Goldmann applanation tonometer, central corneal thickness, Intraocular pressure.
\end{abstract}




\section{Introduction}

Glaucoma has been established as the second leading cause of blindness. The treatment of glaucoma focuses mainly on lowering intraocular pressure (IOP). The target IOP is often set to a level $20 \%$ to $30 \%$ of IOP reduction, and consequent large IOP reduction beyond $30 \%$ or even $40 \%$ in cases of advanced glaucoma.

Intraocular pressure represents a fundamental factor of ocular health and disease. Intraocular pressure is not only important in the diagnosis and management of glaucoma but also in the assessment of postoperative course of all intraocular surgical interventions.

For almost 50 years Goldmann applanation tonometer has been the gold standard for intraocular pressure measurement but its values are affected by central corneal thickness, corneal curvature and axial length, previous corneal surgeries like lasik, keratoplasty, astigmatism and corneal irregularities.

Goldmann applanation tonometer gives correct readings when corneal thickness is 500 to 525micron metre.

Non-contact tonometer has been found to be reasonable for screening but their values should always be correlated with corneal thickness in clinical practice.

Several studies recently have found that thinner than average corneas underestimate, while thicker than average corneas overestimate the true intraocular pressure. This effect has been found to be in the effect of $1 \mathrm{mmhg}$ correction for every 25 micron metre deviation from a central corneal thickness of 550-micron metre.

Tonometry or the measurement of IOP, the pressure of the fluid inside the eye is usually the only modifiable factor in management of all types of glaucoma.

\section{Aims and Objectives of the Study}

1. To compare the intraocular pressure readings of Non-contact, and Goldmann applanation tonometer.
2. To correlate intraocular pressure readings with central corneal thickness.

\section{Materials and Methods}

500 random patients (1000 eyes) attending the ophthalmology outpatient department above the age of 18 years from December 2017 to July 2019 were included in this study.

After taking a proper informed consent a brief history of the purpose of their visit was taken for all patients. Following history taking the distant visual acuity was checked using the Snellen's chart and the near vision was checked using the Jaeger's chart. Once the vision testing was done if the patient had any refractive error an Autorefractometer was used to find out the amount of refractive error followed by an appropriate correction was given for all patients.

Next slit lamp examination was done to rule out any anterior segment pathology like corneal dystrophies, oedema, ulcer, adherent leukoma, acute uveitis, corneal opacities and corneal perforations. This was followed by measurement of the keratometric value using the Autorefractometer.

Then the patient's IOP was recorded first using the non-contact tonometer followed by Goldmann applanation tonometer and all the values were recorded in a proforma. The central corneal thickness for each patient was measured using pachymetry and the values were correlated with IOP.

Following all these examinations dilating drops were put and the fundus evaluation was done using the indirect ophthalmoscope. The posterior segment was evaluated using an ultrasound (BScan) if the patient had any significant cataract or any other media opacities which obscured the view of the retina.

Inclusion Criteria: People aged 18 years to 90 years with no sex predilection.

\section{Exclusion Criteria}

1. Patients with corneal opacities, corneal dystrophies, corneal perforations, infective pathologies like ulcers, leukoma, 
staphyloma, acute uveitis, corneal oedema, acute congestive glaucoma, corneal ectatic conditions.

2. Patients with posterior segment pathologies like retinal detachment, vitreous haemorrhages.

3. Patients not willing to be part of study.

\section{Results}

Table 1

\begin{tabular}{|l|c|c|}
\hline Sex & Number & Percentages \\
\hline Male & 256 & 51.2 \\
\hline Female & 244 & 48.8 \\
\hline Total & 500 & 100.0 \\
\hline
\end{tabular}

Figure 1:

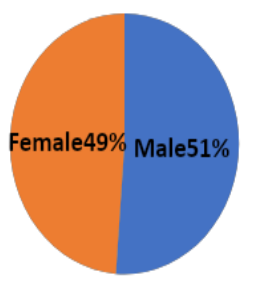

In this study 1000 eyes of 500 patients were taken up. Out of 500 patients 256 were male and 244 patients were female that is $51 \%$ were male and $49 \%$ were female participants.

Table 2: (mean CCT in male and female)

\begin{tabular}{|l|c|c|c|}
\hline & Male & Female & P value \\
\cline { 1 - 3 } Mean & $.5350 \mathrm{~mm}$ & $.5340 \mathrm{~mm}$ & \multirow{2}{*}{0.041} \\
\hline SD & .02829 & .02604 & \\
\hline
\end{tabular}

In this study the mean central corneal thickness (CCT) in males is $0.5350 \mathrm{~mm}$ whereas in females it is $0.5340 \mathrm{~mm}$, which shows that in a general population female have slightly thinner CCTs when compared to males but the values are not statistically significant.

Table 3: (correlation between NCT IOP and GAT IOP)

\begin{tabular}{|l|c|c|c|}
\hline & $\begin{array}{c}\text { NCT (mm } \\
\text { hg) }\end{array}$ & $\begin{array}{c}\text { Goldmann } \\
\text { Applanation } \\
\text { Tonometry (mm hg) }\end{array}$ & p-value \\
\hline $\begin{array}{l}\text { Mean } \\
\text { Std. } \\
\text { Deviation }\end{array}$ & 16.43 & 15.42 & $\mathrm{p}<0.001$ \\
\hline
\end{tabular}

In this prospective study the mean IOP measured by the Goldmann Applanation Tonometer which is considered to be the goldstandard is $15.42 \mathrm{~mm}$ hg which is significantly lower than the mean IOP measured using NCT which is $16.43 \mathrm{~mm} \mathrm{hg}$. Thus, when compared with Goldmann, NCT values are higher and are statistically significant in our study.

When CCT was less than 520-micron metre the mean IOP measured using NCT and GAT were $16.12 \mathrm{~mm}$ hg and $16.90 \mathrm{~mm}$ hg. NCT values were higher than GAT and were statistically significant. Table 4: (correlation between NCT and GAT IOP when CCT is $<=520$ micron metre)

\begin{tabular}{|c|c|c|c|}
\hline \multicolumn{4}{|c|}{$\begin{array}{l}\text { CENTRAL CORNEAL THICKNESS }<=520 \text { - } \\
\text { micron metre }\end{array}$} \\
\hline & NCT & GAT & P value \\
\hline IOP in $\mathrm{mm} \mathrm{hg}$ & 16.12 & 16.90 & \multirow[t]{3}{*}{$<0.001$} \\
\hline SD & 3.98 & 2.76 & \\
\hline Sample size & 270 & 270 & \\
\hline
\end{tabular}

When the corneal thickness was between $520-$ 560 micron metre mean IOP measured by NCT and GAT were $16.23 \mathrm{~mm} \mathrm{hg}$ and $14.91 \mathrm{~mm} \mathrm{hg}$. The NCT values were higher than GAT and were statistically significant.

Table 5: (correlation between NCT and GAT IOP when CCT is 521- 560micron metre)

\begin{tabular}{|c|c|c|c|}
\hline \multicolumn{2}{|c|}{$\begin{array}{l}\text { CENTRAL CORNEAI } \\
\text { 560micron metre }\end{array}$} & \multicolumn{2}{|c|}{ THICKNESS 521} \\
\hline & NCT & GAT & $P$ value \\
\hline IOP in $\mathrm{mm}$ hg & 16.23 & 14.91 & \multirow[t]{3}{*}{$<0.001$} \\
\hline SD & 3.33 & 1.67 & \\
\hline Sample size & 498 & 498 & \\
\hline
\end{tabular}

When CCT was more than 560-micron metre mean NCT IOP was $20.41 \mathrm{~mm}$ hg which is higher than mean GAT value of $15.41 \mathrm{~mm}$ hg and are statistically significant ash shown in table 11 .

Table 6: (correlation between NCT and GAT IOP when CCT is $>560$ micron metre)

\begin{tabular}{|c|c|c|c|}
\hline \multicolumn{4}{|c|}{$\begin{array}{l}\text { CENTRAL CORNEAL THICKNESS >560-micron } \\
\text { metre }\end{array}$} \\
\hline & NCT & GAT & P value \\
\hline IOP in $\mathrm{mm}$ hg & 20.41 & 15.41 & \multirow[t]{3}{*}{$<0.001$} \\
\hline SD & 5.35 & 3.16 & \\
\hline Sample size & 79 & 79 & \\
\hline
\end{tabular}


NCT overestimates IOP for thicker corneas whereas GAT shows higher values when CCT is less than 520-micron metre.

\section{Figure 2:}

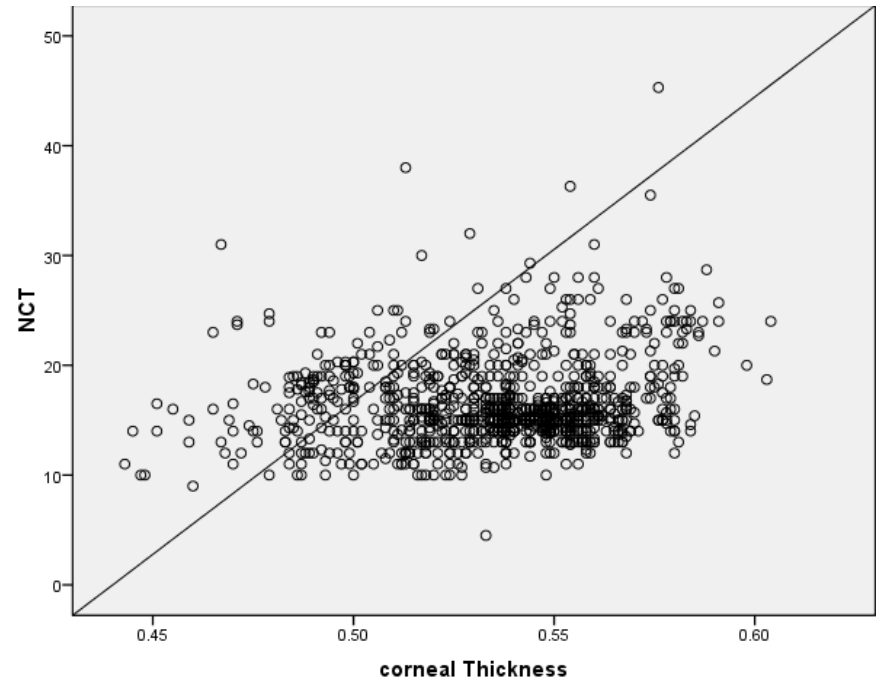

Figure 2 is a scatter diagram showing the correlation between NCT and CCT. NCT values are correlating with $\mathrm{CCT}$ and is statistically significant.

\section{Figure 3:}

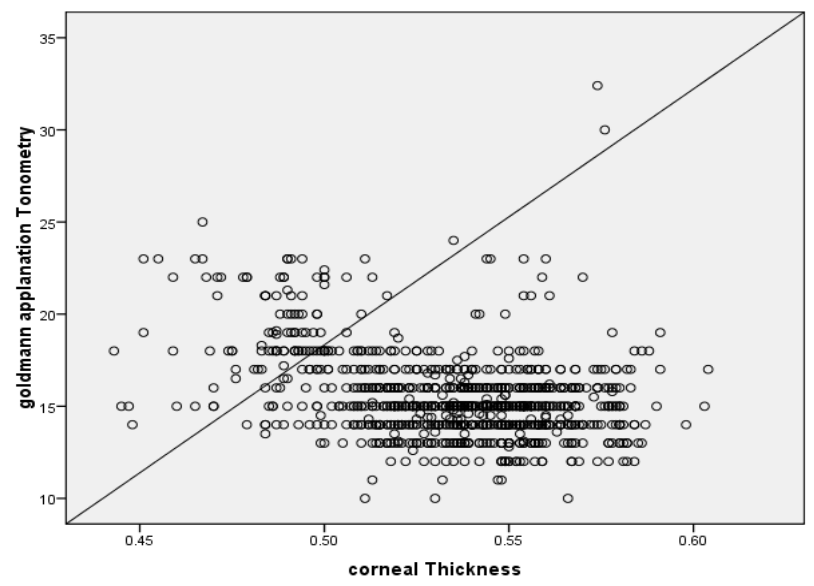

Figure 3 shows the correlation between the IOP measured using GAT and central corneal thickness. Although all the tonometers show statistically significant correlation with CCT but GAT has shown the strongest correlation in this present study. From this we can come to the conclusion that variations in the CCT will affect GAT values more than NCT.

\section{Discussion}

Gunvant et al reported that an increase of $1 \mathrm{~mm}$ of mean corneal thickness was accompanied by a rise in IOP of $1.14 \mathrm{mmHg}$ measured by GAT, but this effect was weak and not statistically significant. ${ }^{1}$ It is now known that GAT values are affected by CCT. In our prospective study we found that all the tonometers that is NCT, and GAT are significantly affected by the CCT of that particular person with GAT showing the strongest correlation followed by NCT in a general population.

Mark suggested that a flatter cornea might lead to lower GAT measurements which is similar to what we found in our study that GAT values are affected by CCT. ${ }^{2}$

Chakrabarty L et al concluded that, NCT and GAT measurements showed good agreements proving that both are reliable methods of measuring IOP. In this study, slight overestimation of IOP measurement was found by NCT in lower IOP ranges $(<12 \mathrm{mmHg})$. Contrary to some studies, good correlation between GAT and NCT in higher IOP ranges was found. ${ }^{3}$

In our study we found NCT values were significantly higher than that of GAT and the values were statistically significant.

Shih et al. had an objective to ascertain whether CCT affected patient management. Their study, although set within a specialist glaucoma service, showed that half their study population required an adjustment of IOP $\pm 1.5 \mathrm{mmHg}$. What is interesting is that $8-10 \%$ of their cohort had a change in their medication. ${ }^{4}$

In a study by Ehlers et al, a manometric, controlled closed system was used to examine the correlation between CCT and IOP measured by applanation tonometry in 29 patients. Ehlers et al reported an error of $\pm 0.71 \mathrm{~mm} \mathrm{Hg}$ between real IOP and IOP measured by applanation tonometry per $10-\mu \mathrm{m}$ difference in CCT. Corneal curvature affected IOP readings in the study by Ehlers et al. ${ }^{5}$ In the present study also both the NCT and GAT values were significantly affected by the CCT of that particular person. NCT shows higher values for thicker corneas whereas GAT shows higher IOP when CCT is less than 520-micron metre. 
Ismail et al reported that in eyes that had undergone penetrating keratoplasty, GAT measurements may be less precise than nonapplanation tonometry because all these patients will not have normal CCT post-surgery. These findings are also similar to what we found in our study that GAT values are affected by CCT and although it is the gold standard true IOP should be recorded in all patients so that the CCT of that particular person is also taken into account. ${ }^{6}$

Kirwan et al, found that the mean GAT IOP decreased $3.7+/-2.3 \mathrm{~mm} \mathrm{Hg}$ following LASIK, and a similar decrease was observed following LASEK. ${ }^{7}$

Milla et al. found an optimal agreement between DCT and GAT when the CCT was between 540 and $545 \mu \mathrm{m}$. As the CCT and the IOP increase, the difference between both tonometers also increases. ${ }^{8}$

Francis et al reported that $\mathrm{K}$ (corneal curvature) affects DCT readings. ${ }^{9}$

Medeiros et al, reported that $\mathrm{K}$ affects GAT readings. $^{10,11}$

S. Nagarajan et al concluded that both Schiotz and NCT showed significant correlation with the gold standard technique over a range of IOP and CCT with the Schiotz tonometer performing better than NCT. ${ }^{12}$

In two studies in which the Reichert NCT was used (Jorge et al.2002; Jorge et al.2003) was used both in normal subjects and patients with glaucoma, excellent agreement with GAT measurements was observed which is contrary to what we found in our study where there was significant difference between NCT and GAT readings with NCT readings being significantly higher than GAT readings in a general population. $^{13}$

However, Domke et al. 2006 noted that measurements of Reichert NCT are conditioned by CCT. which is similar to our findings where NCT readings were influenced by CCT. ${ }^{14}$

NCT values are higher for thicker corneas whereas GAT values are higher for thinner corneas.
Parker et al. compared NCT and GAT and found results were concordant between the two devices which is different from what we found in our large prospective study. ${ }^{16}$

In another study, Tonnu et al. compared NCT, TPXL, and GAT and reported that all three devices showed homologous results. ${ }^{15}$

Farhood showed that NCT and GAT were not well correlated, and NCT measurements gave higher IOP results regardless of the patient's age or sex. In particular, when the GAT measurement exceeded $24 \mathrm{mmHg}$, the difference in readings between the two instruments increased. Farhood reported that the lower the IOP as measured by GAT, the more reliable the corresponding NCT readings. ${ }^{17}$

This is in accordance to what we reported in our study.

The NCT and TPXL are easier and faster to use than the GAT, but suspicions about their results still exist. Yilmaz et al. found no significant differences between these three devices in normotensive patients. ${ }^{18}$

Feng et al. also found the noncontact tonometry to overestimate IOP relative to GAT for thicker CCT which is similar to what we found in our study. $^{22}$

Loewen et al reported that AXL had a significantly negative correlation with $24 \mathrm{~h}$ IOP fluctuation. ${ }^{19}$

Lee SY et al said in their study central corneal thickness (CCT), corneal curvature (CC), and axial length (AXL) demonstrated significant correlation with GAT fluctuation in the high IOP fluctuation group, and AXL showed significant correlation with DCT fluctuation in the low IOP fluctuation group. We only found CCT to significantly affect IOP readings in the 2 tonometers used by us. ${ }^{20}$

Cook et al. conducted a meta-analytical study comparing 8 tonometers and concluded that GAT continues to be the gold standard. It was observed that NCT was having least disagreement with GAT which is again contrary to what we found in the present study. ${ }^{23}$ 
Although NCT is also widely used the correlation observed between measurements obtained using this type of tonometry and conventional applanation tonometry has never been particularly good (Vernon 1995; Tonnu et al. 2005; Lafaut et al. 2007; Ogbuehi \& Almubrad 2008). ${ }^{15,24,25,26,27}$

Studies conducted by (Grieshaber MC et al, Kamppeter BA et al, Kaufmann $\mathbf{C}$ et al) have reported a significant positive correlation between GAT and CCT similar to our study. ${ }^{28,29,30}$

Studies conducted by Schneider $\mathbf{E}$ et al, Kniestedt C et al, Ku JY et al found no correlation between GAT values and central corneal thickness which is contrary to what we found in our large prospective study. ${ }^{31,32}$

Y. Harada et al found central corneal thickness significantly correlated with IOP measured by NCT and that measured by GAT. Corneal curvature radius significantly correlated with IOP measured by GAT, however not significantly correlated with that measured with NCT. ${ }^{34}$

Punit Singh et al concluded that IOP measured by both NCT and GAT was significantly correlated with CCT. NCT readings were significantly higher in the thicker group (CCT>or=530 micron) than in the thinner group (CCT $<530$ micron). GAT readings had no difference between the thicker and thinner groups. $^{35}$

Babalola et al and Tonnu et al also showed that changes in IOP measured with NCT are more dependent on CCT than IOP measured by Goldmann tonometer. ${ }^{15,36}$

Behrooz Kouchaki et al found a linear relationship between IOP and CCT. ${ }^{37}$

\section{Conclusion}

IOP measurement is one of the most important investigation that an ophthalmologist will do in his daily practise. It has got immense importance as it is one of the risk factors of glaucoma and is also the only modifiable risk factor in glaucoma. So, an accurate measurement of the IOP is of paramount importance in the general population in order to say whether the person is at risk of developing glaucoma or has glaucoma.

Goldmann applanation tonometer has been the gold standard for measuring IOP since it was discovered. Although it has been the gold standard it has its own advantage and disadvantages. Many other tonometers are there which work on the applanation principle as well as on other principles but has not been able to replace Goldmann as the goldstandard.

It has been well documented in literature that Goldmann values are affected by CCT and also there are disadvantages like chances of infection and there is a learning curve to mention a few.

On evaluating 500 patients and 1000 eyes we came to the conclusion that NCT values are higher than that of GAT and they are statistically significant. NCT values were higher for thicker corneas and GAT values were higher for thinner corneas in a general population.

When the correlation of CCT with IOP measured by all these tonometers were assessed we found that all the tonometers were significantly affected by CCT. The correlation was statistically significant and we found that Goldmann values are more likely to be affected by CCT followed by NCT. So, from the present study we can conclude that the 2 tonometers are reliable and can be used in the daily practice of an ophthalmologist. When CCT was taken into account we found it affected GAT readings the most followed by NCT. So, it is always advisable to calculate the corrected IOP in all patients so that we can get the exact IOP of that particular person.

\section{References}

1. Gunvant P, Baskaran M, Vijaya L, Joseph IS, Watkins RJ, Nallapothula $M$, Broadway DC, O'Leary DJ. Effect of corneal parameters on measurements using the pulsatile ocular blood flow tonograph and Goldmann applanation tonometer. Br J Ophthalmol 2004; 88(4):518-522. 
2. Mark HH. Corneal curvature in applanation tonometry. Am J Ophthalmol 1973; 76(2):223-224.

3. Chakrabarty L. Goldmann applanation tonometry versus non-contact tonometry: a comparative study. Int J Res Med Sci 2016; 4:4683-7.

4. Shih CY, Graff-Zivin JS, Trokel SL, Tsai JC: Clinical significance of central corneal thickness in the management of glaucoma. Arch Ophthalmol 2004, 122:1270-1275.

5. Ehlers $\mathrm{N}$, Bramsen $\mathrm{T}$, Sperling $\mathrm{S}$ : Applanation tonometry and central corneal thickness. Acta Ophthalmol (Copen) 1975; 53:34-43.

6. Ismail AR, Lamont $\mathrm{M}$, Perera $\mathrm{S}$. Comparison of IOP measurement using GAT and DCT in patients with penetrating keratoplasties. Br J Ophthalmol. 2007; 91:980-981.

7. Kirwan C, O'Keefe M. Measurement of intraocular pressure LASIK and LASEK patients using the Reichert Ocular Response Analyzer and Goldmann applanation tonometry. J Refract Surg. 2008; 24:366-70.

8. Milla E, Duch S, Buchacra O, Masuet C. Poor agreement between Goldmann and Pascal tonometry in eyes with extreme pachymetry. Eye 2008; 28.

9. Francis BA, Hsieh A, Lai MY, Chopra V, Pena F, Azen S, et al., Los Angeles Latino Eye Study Group. Effects of corneal thickness, corneal curvature, and intraocular pressure level on Goldmann applanation tonometry and dynamic contour tonometry. Ophthalmology 2007; 114: 20-26.

10. Medeiros FA, Sample PA, Weinreb RN. Comparison of dynamic contour tonometry and Goldmann applanation tonometry in African-American subjects. Ophthalmology 2007; 114: 658-665.

11. Medeiros FA, Weinreb RN. Evaluation of the influence of corneal biomechanical properties on intraocular pressure measurements using the ocular response analyzer. J Glaucoma 2006; 15: 364-370.

12. Swathi Nagarajan; Veerabahu Velayutham; G Ezhumalai. Comparative evaluation of applanation and indentation tonometers in a community ophthalmology setting in southern India. Saudi Journal of Ophthalmology (2016) 30:83-87.

13. Jorge J, Diaz-Rey JA, Gonzalez-Meijome JM, Almeida JB, Parafita MA. Clinical performance of the Reichert AT 550: new noncontact tonometer. Ophthalmic Physiol Opt. 2002; 22:560-4.

14. Domke N, HagerA \& Wiegand W (2006): Intraocular pressure and corneal thickness. A comparison between non-contact tonometry and applanation tonometry Oph-thalmologe103: 583-587.

15. Tonnu PA, Ho T, Newson T, El Sheikh A, Sharma K, White $\mathrm{E}$ et al. The influence of central corneal thickness and age on intraocular pressure measured by pneumotonometry, non-contact tonometry, the Tono-Pen XL, and Goldmann applanation tonometry. $\mathrm{Br} \mathrm{J}$ Ophthalmol 2005; 89: 851-854.

16. Parker VA, Herrtage J, Sarkies NJ. Clinical comparison of Keeler Pulsair 3000 with Goldmann applanation tonometry. $\mathrm{Br}$ J Ophthalmol. 2001; 85:1301-4.

17. Farhood QK. Comparative evaluation of intraocular pressure with an air-puff tonometer versus a Goldmann applanation tonometer. Clin Ophthalmol. 2013; 7:2327.

18. Yilmaz I, Altan C, Aygit ED, Alagoz C, Baz O, Ahmet S, Urvasizoglu S, Yasa D, Demirok A. Comparison of three methods of tonometry in normal subjects: Goldmann applanation tonometer, noncontact airpuff tonometer, and Tono-pen XL. Clin Ophthalmol. 2014; 8:1069-74. 
19. Loewen NA, Liu JH, Weinreb RN. Increased 24-hour variation of human intraocular pressure with short axial length. Invest Ophthalmol Vis Sci. 2010; 51(2):933 \pm 7 .

20. Lee SY, Bae HW, Kwon HJ, Seong GJ, Kim CY (2018) Utility of Goldmann applanation tonometry for monitoring intraocular pressure in glaucoma patients with a history of laser refractory surgery. PLoS ONE 13(2): e0192344.

21. S-Y Hsu, M-M Sheu, A-H Hsu, K-Y Wu, J-I Yeh, J-N Tien and R-K Tsai. Comparisons of intraocular pressure measurements: Goldmann applanation tonometry, noncontact tonometry, TonoPen tonometry, and dynamic contour tonometry. Eye (2009) 23, 1582-1588.

22. Feng, Chi Shian. Comparison of Intraocular Pressure Measurements Obtained by Rebound, Noncontact, and Goldmann Applanation Tonometry in Children. American Journal of Ophthalmology, Volume 160; Issue 5: 937 $-943$.

23. Cook JA, Botello AP, Elders A, Fathi Ali A, Azuara-Blanco A, Fraser C, et al. Systematic review of the agreement of tonometers with Goldmann applanation tonometry. Ophthalmology. 2012; 119:1552-7.

24. Vernon SA. Reproducibility of Keeler Pulsair 2000 non-contact tonometer. Br J Ophthalmol.1995; 79: 554-557.

25. Lafaut AS, Van Malderen L \& Zeyen T. Is pulse synchronized pneumotonometry more reproducible than routine pneumotonometry and more in agreement with Goldmann applanation tonometry? Eur J Ophthalmol.2007; 17: 178-182.

26. Ogbuehi KC \& Almubrad TM. Accuracy and reliability of the Keeler Pulsair EasyEye non-contact tonometer. Optom Vis Sci.2008; 85: 61-66.
27. Ogbuehi KC. Assessment of the accuracy and reliability of the Topcon CT80 noncontact tonometer. Clin Exp Optom.2008; 89: 310-314.

28. Grieshaber MC, Schoetzau A, Zawinka C. Effect of central corneal thickness on dynamic contour tonometry and Goldmann applanation tonometry in primary openangle glaucoma. Arch Ophthalmol 2007; 125:740-744.

29. Kamppeter BA, Jonas JB. Dynamic contour tonometry for intraocular pressure measurement. Am J Ophthalmol 2005; 140:318-320.

30. Kaufmann C, Bachmann LM, Thiel MA. Comparison of dynamic contour tonometry with Goldmann applanation tonometry. Invest Ophthalmol Vis Sci 2004; 45:3118-3121.

31. Schneider E, Grehn F. Intraocular pressure measurement-comparison of dynamic contour tonometry and Goldmann applanation tonometry. J Glaucoma 2006; $15: 2$

32. Kniestedt C, Lin S, Choe J. Clinical comparison of contour and applanation tonometry and their relationship to pachymetry. Arch Ophthalmol 2005; 123:1532-1537.

33. Ku JY, Danesh-Meyer HV, Craig JP. Comparison of intraocular pressure measured by Pascal dynamic contour tonometry and Goldmann applanation tonometry. Eye 2006; 20:191-198.

34. Y. Harada, N. Hirose, T. Kubota, A. Tawara. The Influence of Central Corneal Thickness and Corneal Curvature on Intraocular Pressure Measured by Different Tonometers; Non-Contact and Goldmann Applanation Tonometers. Invest. Ophthalmol. Vis. Sci. 2006;47(13):4457.

35. Punit Singh, Raghunandan Kothari, Himadri Patel. The influence of central corneal thickness on intraocular pressure, 
measured by different tonometers:

Noncontact and Goldmann applanation tonometers. National journal of medical research. Volume 7(1): Jan - Mar 2017.

36. Babalola OE, Kehinde AV, Iloegbunam AC, Akinbinu T, Moghalu C, Onuoha I. A comparison of the Goldmann applanation and non-contact (Keeler Pulsair EasyEye) tonometers and the effect of central corneal thickness in indigenous African eyes. Ophthalmic Physiol Opt. 2009;29(2):182-188.

37. Behrooz Kouchaki, Hassan Hashemi, Abbasali Yekta, Mehdi khabazkhoob. Comparison of current tonometry techniques in measurement of intraocular pressure. Journal of Current Ophthalmology.2017; 29:92-97. 